\title{
Integration of a Water Quality Laboratory Sequence into a Core Chemistry Course
}

\section{Dr. Elizabeth Mentis, United State Military Academy}

Dr. Beth Mentis is an Assistant Professor in the Department of Chemistry \& Life Science at the United States Military Academy where she currently teaches General Chemistry. With a background in analytical chemistry, she explores research topics such as utilizing mass spectrometric analysis to explore questions relevant to atmospheric chemistry. Her current research centers on characterizing microbial samples with MALDI-TOF MS.

\section{Lt. Col. Andrew Ross Pfluger, United States Military Academy}

Lieutenant Colonel Andrew Pfluger, U.S. Army, is an Assistant Professor in the Department of Chemistry \& Life Science of the U.S. Military Academy (USMA) at West Point. He has earned a B.S. in Civil Engineering from USMA, a M.S. and Engineer Degree in Environmental Engineering and Science from Stanford University, and a Ph.D. in Civil \& Environmental Engineering from the Colorado School of Mines. He is also a licensed PE in the state of Delaware.

\section{Dr. April Dawn Miller, United States Military Academy}

LTC April Miller was commissioned in the United States Army in 2000 and has served in many positions. She obtained a BS in Chemical Engineering from Clarkson University, a MS in Environmental Management from Webster University, a MS in Nuclear Engineering from Air Force Institute of Technology and a PhD in Chemical and Biomolecular Engineering from University of Nebraska-Lincoln. She currently is an Assistant Professor at the United States Military Academy.

\section{Dr. Enoch A. Nagelli, United States Military Academy}

Dr. Enoch Nagelli is an Assistant Professor in the Chemical Engineering Program. He teaches core chemical engineering courses. He earned his Ph.D. degree in Chemical Engineering from Case Western Reserve University in August 2014. His Ph.D. dissertation work was on the controlled synthesis, functionalization and assembly of carbon nanomaterials for energy storage and conversion applications. Following his doctoral studies, Dr. Nagelli worked as a post-doctoral researcher in the Electrochemical Engineering and Energy Laboratory at Case Western Reserve University. In this role, he worked on the performance diagnostics of flowable slurry electrodes for redox flow batteries and electrochemical flow capacitors. His research interest includes the fundamental understanding of the influence of surface chemistry of carbon nanomaterials in electrochemical applications, flowable slurry electrodes, development of flow-assisted electrochemical energy systems (fuel cells, flow batteries, flow capacitors), and mass/charge transport phenomena and reaction kinetics in electrochemical systems. He is a member of the American Institute of Chemical Engineers, the American Chemical Society, and the Electrochemical Society. 
Title: Integration of a water quality laboratory sequence into a core chemistry course

\begin{abstract}
:
According to the President's Council of Advisors on Science and Technology, less than 40\% of students entering college intending to major in STEM-related fields graduate with a STEM degree. High-performing students frequently credit uninspiring introductory courses for their change in direction. Introductory courses in the Department of Chemistry and Life Science at the United States Military Academy include two semesters of general chemistry. General Chemistry II is a core chemistry course required for Chemical Engineering, Chemistry, Kinesiology, Life Science, Environmental Engineering, Environmental Science and Mechanical Engineering majors; students preparing for medical school; or as a science elective. The roughly 200 students enrolled each semester are divided into sections of approximately 20 students taught by 6 faculty members. To improve student engagement in General Chemistry II, a research inspired, water quality themed laboratory sequence was implemented beginning in the Spring 2017 semester. The water quality laboratory sequence consists of four introductory skill-building labs followed by three labs during which students tour a water treatment facility, then collect and analyze water samples of their choice. Students collect samples from water sources near the student living area, to include treated tap water, an estuary, and a reservoir. Examples of water quality analyses students complete include titrimetric methods, which are applied to measure parameters such as total hardness and total alkalinity; and UV-Vis spectroscopy to measure dissolved iron. The goal of the new laboratory sequence was to implement the following key elements: (1) support content goals of the course; (2) be hands-on; (3) balance expository and inquiry-based instruction; (4) be feasible to implement with available resources; and (5) promote a constructive affective learning environment. The first four elements listed above were assessed based on alignment with course learning objectives and American Chemical Society guidelines and analysis of the data generated by students in the laboratory. The final element was assessed based on feedback from students. More than half of the students surveyed each semester reported the lab sequence increased their level of interest in pursuing research in a STEM field. These preliminary findings suggest the water quality themed lab sequence was successful in improving student engagement and maintaining or increasing level of interest in STEM-related fields.
\end{abstract}




\section{Introduction}

More than two decades ago, the National Science Education Standards recommended a transition from traditional expository to inquiry-based curricula in the science classroom. This recommendation stemmed the development of standards and frameworks built upon inquirybased methods (National Research Council, 1996 and 2012; Cooper, 2013; Bybee, 2014). The belief is that inquiry-based learning will not only improve students' knowledge of science, but it will also improve their ability to think critically and creatively about the natural world (Maienschein, 1998). Introduction of a new approach, such as inquiry-based learning, could also be a useful intervention to increase the percentage of students that remain in STEM related fields. Studies have determined that less than $40 \%$ of students entering college intending to major in STEM related fields graduate with a STEM degree. One of the reasons high-performing students frequently give for changing majors is uninspiring introductory courses (National Research Council, 2014). Given a historical reputation of emphasizing rote memorization, it is necessary to evaluate the teaching approaches and learning experiences in general chemistry curriculum not only to improve retention in STEM fields, but also to improve scientific literacy in general (Korn, 2015).

To improve scientific literacy, the Chemistry Program in the Department of Chemistry and Life Science (CLS) at the United States Military Academy (USMA) in West Point, NY implemented an inquiry-based learning approach in our General Chemistry I (CH101) and General Chemistry II (CH102) courses in 2015. Approximately 1100 students each year take CH101 - a required course, while approximately 400 students each year take CH102. In 2017 our institution increased the depth of CH102's inquiry-based learning approach with the introduction of a water quality laboratory sequence. We used five key elements to develop the laboratory curriculum. First, we determined that the laboratory curriculum must satisfy the course goals, which broadly included learning safe laboratory practices, developing data analysis skills, and developing laboratory techniques required for more advanced STEM courses (American Chemical Society Committee on Professional Training, 2015). Second, we determined that laboratory work should primarily be a hands-on experience in which students are provided the opportunity to carry out experiments themselves (Larsen, et al. 2013; Obenland, et al., 2014). Third, we determined the introductory laboratory curriculum should be a balance of expository and inquiry instruction and, if possible, an introduction to independent research techniques (Svinicki and McKeachie, 2014; Tomasik, et al. 2013; Galloway, et al., 2016). Fourth, the laboratory program must be feasible within available resources, which included time, costs, instrumentation, physical facilities, and support personnel (Larsen, et al. 2013). Fifth, we developed the laboratory curriculum to promote a more complex affective learning environment. Galloway et al. showed that accessing feelings beyond interest about the laboratory experience encourages students to make a conscious choice to more actively participate in the laboratory learning environment (2016).

\section{Course Description and Demographics}

USMA is an undergraduate institution where all graduates earn a Bachelor of Science degree and are commissioned as officers in the United States Military. Our institution has a robust core curriculum, which includes 24-27 required courses for all students (depending on the major). All 
students at USMA are required to take introductory physics, physical geography, and general chemistry (i.e., CH101); however, CH102 is only required for certain STEM majors, to include Chemical Engineering, Chemistry, Kinesiology, Life Science, Environmental Engineering, Environmental Science and Mechanical Engineering. $\mathrm{CH} 102$ can also be taken as a science elective by students majoring in other disciplines. Figure 1 depicts demographics of the 231 students surveyed in Spring 2017 and Spring 2018. As shown, more than $75 \%$ of students taking CH102 come from STEM majors.

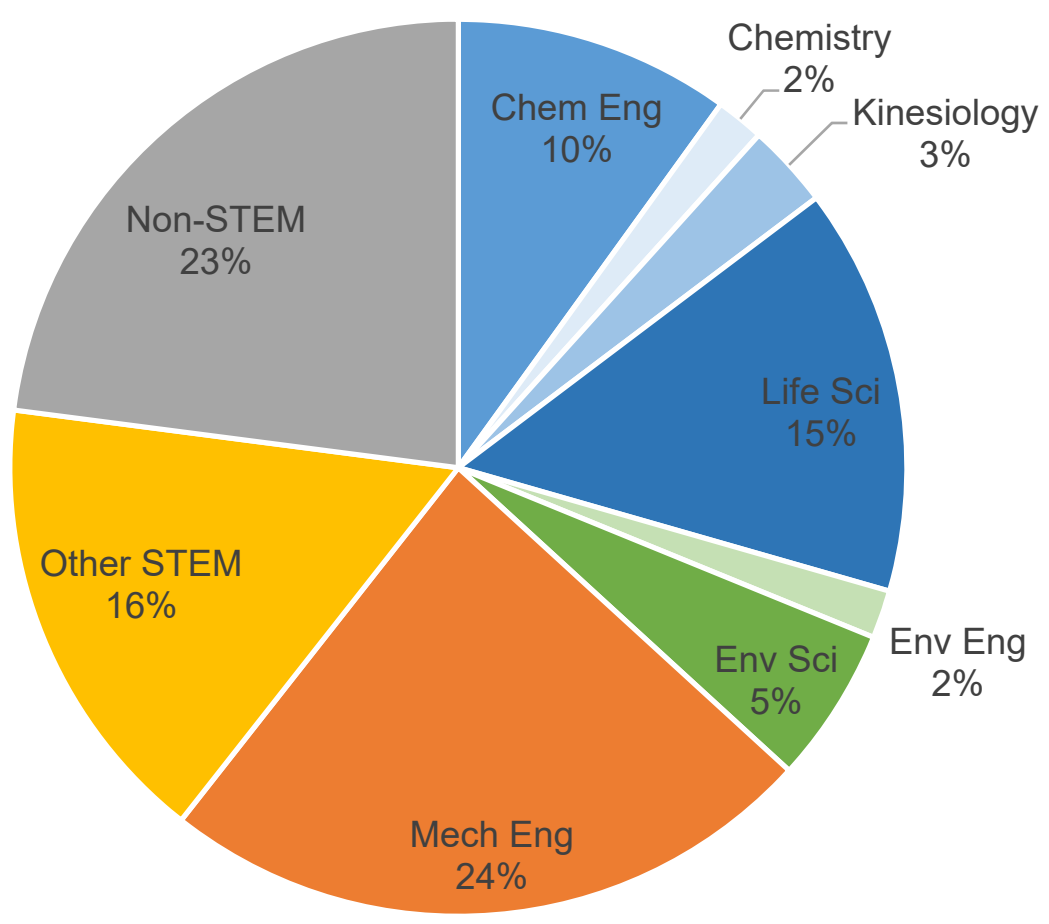

Figure 1. Student demographics by major. Majors that require $\mathrm{CH} 102$ shown explicitly; remaining majors/programs consolidated as STEM (e.g. Physics, Computer Science, Mathematics) or non-STEM (e.g. English, Philosophy, Foreign Language). The figure is a composite of 113 students from 2017 and 118 from 2018. Both values exceed 50\% of total students enrolled and the distributions of majors each semester are consistent.

CH102 is designed to extend foundational disciplinary content from the first semester of general chemistry into new topic areas, which include equilibrium, solubility, acid/base chemistry, electrochemistry, thermodynamics (entropy and free energy) and kinetics. Basic principles governing organic chemistry are also addressed. The course is taught in both the fall and spring semesters by approximately six instructors, who hold either doctorates of philosophy or master's degrees in a relevant discipline (e.g., analytical chemistry, biochemistry, chemical engineering). There are 40 class meetings for $\mathrm{CH} 102$. These meetings are divided into 32 eighty-minute classroom lessons and 8 two-hour laboratory lessons. The laboratory meetings are distributed throughout the course to align with lesson material as it is presented. 


\section{Description of Water Quality Laboratory Sequence}

Historically, the lab sequence in $\mathrm{CH} 102$ relied heavily on expository instruction in the form of verification labs. Detailed procedures were provided to students and post-lab questions reviewed what was observed. However, the structured procedures were restrictive thereby limiting opportunities for creativity and critical thinking (Galloway, 2016). For Spring 2016 and Fall 2016, the lab curriculum was significantly modified with the goal of providing students with an authentic research experience. The revised lab sequence followed the structure described by the Center for Authentic Science Practice in Education (CASPiE) (Chase et al., 2017). Table 1 shows lab titles from Spring 2011 and Fall 2016 illustrating the change in approach with the CASPiE structure. Under the CASPiE approach, students optimized extraction protocols and compared their results with published values in the literature. While contributing to a research project was appealing to students, difficulties arose with establishing a new research topic each semester; linking the topic to lesson learning objectives; and creating a project at an appropriate skill level for CH102 students to do meaningful research.

Table 1. CH102 laboratory sequence prior to Spring 2017. The lesson number shows where the lab is located in the 40 class meetings for the course.

\begin{tabular}{clcl}
\hline Lesson & \multicolumn{1}{c}{ Topic (Spring 2011) } & Lesson & \multicolumn{1}{c}{ Topic (Fall 2016) } \\
\hline 04 & Polymers & 07 & Reading a Scientific Paper \& Introduction to Project \\
06 & Kinetics & 12 & Skill Building: Beer's Law \& Calibration Curves \\
15 & Equilibrium Constant & 20 & Skill Building: Extraction \\
22 & Buffers & 30 & \\
24 & Solubility Product & 31 & Student Experiments 1-3: Implementation and \\
30 & Thermodynamics II & 32 & Evaluation of Proposed Extraction Methods \\
33 & Voltaic Cells & 33 & Data Analysis \& Poster Prep \\
40 & Clean Coal & 39 & Poster Presentation \\
\hline
\end{tabular}

Water quality was selected as the laboratory theme in Spring 2017 due to its applicability to numerous academic disciplines as well as everyday life. On average, adults need to consume approximately 2 liters of water-containing beverages per day. Water helps regulate numerous functions in the body, including temperature and nutrient uptake (Mayo Clinic, 2017). In 2015, 663 million people still relied on unimproved water sources, while approximately 1.8 billion people used a drinking-water source contaminated with feces. From an economic perspective, access to improved water supply and sanitation and better management of water resources can boost a country's economic growth and can greatly reduce poverty (World Health Organization, 2018). Additionally, graduates from our institution are particularly concerned with sustained provision and use of clean, potable water in austere environments. A thorough understanding of the importance of water quality can have a direct positive impact on the safety of soldiers. 
The water quality laboratory sequence developed includes 7-8 laboratory experiences, which are listed in Table 2 . The book that guided the student experience in our laboratory sequence was Water Treatment: How Can We Make Our Water Safe to Drink (Kegley et al., 2004). Instructors also used the associated laboratory guidebook (Kegley et al., 2003). The laboratory sequence began with three or four skill building labs that introduced analytical techniques for measuring hardness, total dissolved solids, $\mathrm{pH}$, iron, and alkalinity in water samples. Students also toured our institution's water treatment plant after which student groups collected water samples from various water sources to analyze over the following three lab periods (listed in Table 2 as "Water Sample Analysis"). Four class periods were allocated at the end of the course to assessing the analyzed data and preparing and presenting a poster.

Table 2. CH102 laboratory sequence. Each lab sequence concluded with four lessons dedicated to data analysis, poster preparation and practice, and a final poster presentation.

\begin{tabular}{clcl}
\hline Lesson & \multicolumn{1}{c}{ Topic (Spring 2017) } & Lesson & \multicolumn{1}{c}{ Topic (Spring 2018) } \\
\hline 07 & Total Hardness Titration & 07 & Total Dissolved Solid Measurement \\
15 & Total Alkalinity Titration & 12 & Total Alkalinity Titration \\
20 & Total Dissolved Iron (Spectrophotometry) & 19 & Remediating / Quantifying Hardness \\
24 & Total Dissolved Solid and pH Measurement & 21 & Water Treatment Plant Tour \\
28 & Hypothesis Selection \& Experimental & 29 & Hypothesis Selection \& \\
& Design & & Experimental Design \\
29 & Water Treatment Tour \& Sample & & \\
30 & Collection & 30 & Water Sample Collection \& Analysis \\
31 & Water Sample Analysis & 31 & Water Sample Analysis \\
32 & Water Sample Analysis & 32 & Water Sample Analysis \\
\hline
\end{tabular}

Students were required to maintain individual laboratory notebooks, which included answers to pre- and post-lab questions. For two of the initial introductory labs, students were required to prepare lab reports (one per group of 2-3 students). Prior to collecting water samples for analysis, students developed individual research proposals. Subsequent analysis of samples and assessment of data were conducted in student groups consisting of 3-4 students. One comprehensive poster was prepared per student group which summarized findings and proposed additional water treatment strategies. The posters were presented in an open forum to the USMA community.

\section{Methods of Assessment}

To assess the efficacy of the research-inspired water quality sequence on actively engaging and inspiring students in the laboratory, students from Spring semesters in 2017 and 2018 were surveyed. In 2017, students were surveyed once at the end of the semester. In 2018, students 
were surveyed on two occasions: once before starting the laboratory sequence and once at the end of the semester. Survey questions were based on student self-assessment of proficiency of the laboratory techniques, instruments and skills listed in Figure 2. Students were asked at the beginning of the semester to indicate if they have no experience or extensive experience with each of the items. No response was used to indicate average, introductory knowledge.

\begin{tabular}{|c|c|c|}
\hline Titrations & Spectrophotometry & pH probe \\
\hline Conductivity probe & Volumetric glassware & Air displacement pipette \\
\hline Maintaining a lab notebook & Writing a lab report & Data analysis \\
\hline
\end{tabular}

Figure 2. Matrix of laboratory techniques, instruments, and skills on survey. Students were asked on the initial assessment to place a star next to items with which they have little to no experience and circle items with which they have extensive experience. In the final survey, students were asked to circle items for which they felt the laboratory improved their level of understanding and cross out the items for which their level of understanding was not improved. No response was an option in both surveys.

Students were also asked to provide feedback on the affective learning environment by indicating descriptive terms they did and did not associate with their laboratory experience. A word frequency analysis was then conducted, as described in Galloway et al. (2016). Figure 3 shows the 18 terms used to assess the learning environment in the lab.

\begin{tabular}{|c|c|c|}
\hline Intimidated & Motivated & Nervous \\
\hline Confident & Confused & Anxious \\
\hline Interested & Worried & Excited \\
\hline Afraid & Lost & Comfortable \\
\hline Organized & Frustrated & Inspired \\
\hline Creative & Bored & Challenged \\
\hline
\end{tabular}

Figure 3. Matrix of affective words. Students indicated feelings experienced in the lab by circling terms and feelings not experienced in the lab by crossing out a term. In 2018, the initial survey requested assessment based on previous chemistry courses while the final survey focused on work completed in the lab in $\mathrm{CH} 102$.

In total, 113 of 186 students enrolled in Spring 2017 and 118 of 223 students enrolled in Spring 2018 completed surveys. Surveys were only administered to sections of two faculty members 
each year. One faculty member had previous experience teaching the course while the other was new to teaching the course. In addition to survey responses, student performance on the American Chemical Society (ACS) Full Year General Chemistry standardized exam, which was given at the conclusion of the course, was also incorporated into the assessment.

\section{Results and Discussion}

\subsection{Improvement in Laboratory Techniques, Instruments, and Skills}

Based on student self-assessment, students typically had little to no experience working with conductivity probes, spectrophotometers, and air displacement pipettes prior to taking $\mathrm{CH} 102$. However, most students had prior experience with data analysis, using volumetric glassware, and preparing laboratory reports before taking the course.

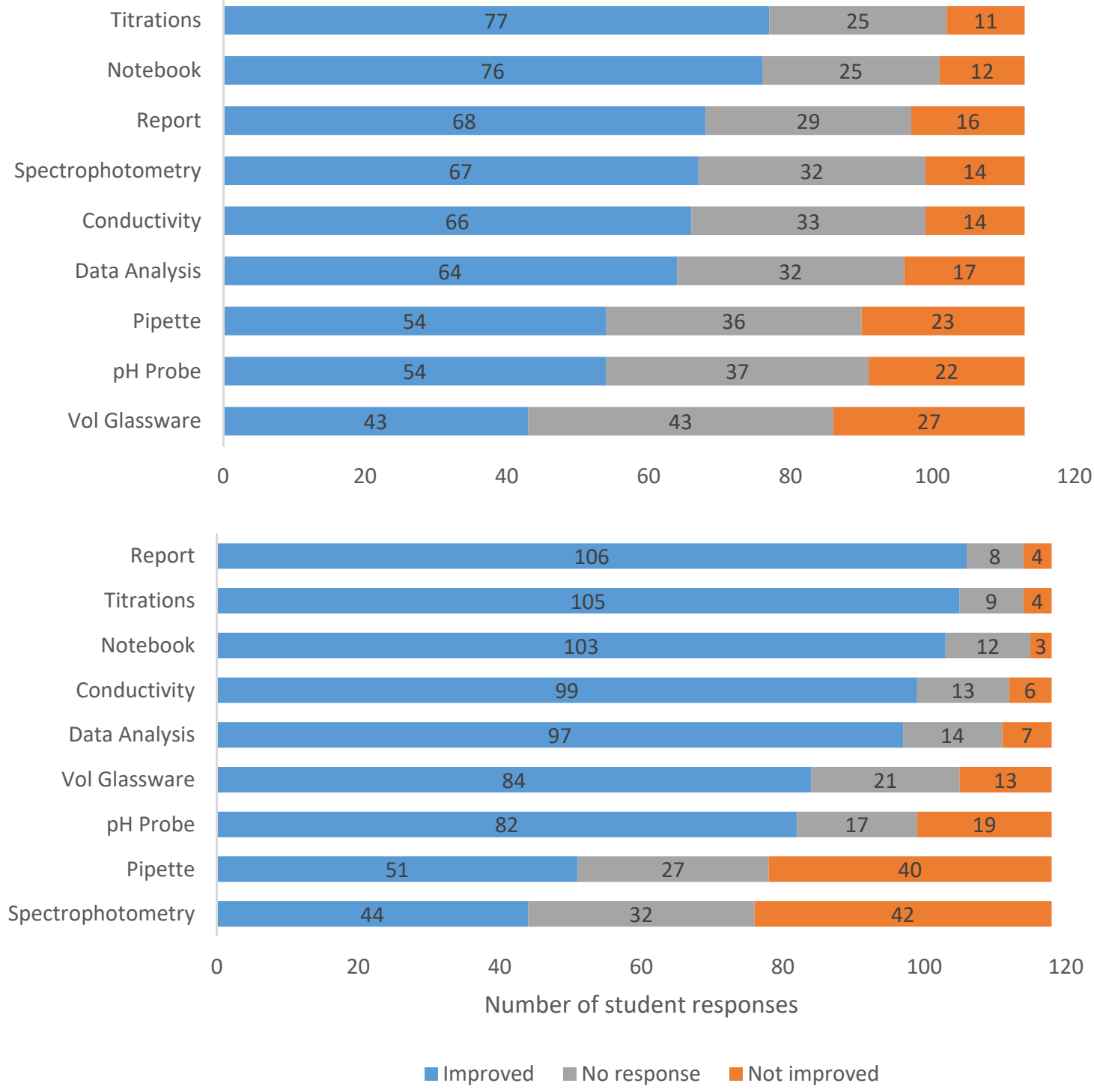


Figure 4. Results from student self-assessment of contribution of laboratory sequence to improving level of understanding with laboratory techniques, instruments, and skills. Top panel summarizes results from 2017 and bottom panel from 2018 survey. Bands in blue indicate an improved response (left side of bar graph); orange indicate the field was not improved by the sequence (right side); and grey indicate no response (middle field).

Student self-assessment in 2017, summarized in Figure 4, was correlated to reported results from the water sample analysis. For example, 11 groups collected samples from one specific dormitory. The hardness of those samples was determined by titration with EDTA to be $29 \pm 6$ $\mathrm{ppm} \mathrm{CaCO}_{3}$ after discarding only one outlier. This measured value is within one standard deviation of the hardness of the natural water source for the dormitory reported by other groups. The consistent data collected by different groups supports the conclusion that students were proficient in completing titrimetric analyses.

From 2017 to 2018, an increased number of students responded that the lab sequence did 'not improve' their level of understanding of spectrophotometry or experience in using air displacement pipettes as shown in Figure 4. This is likely due to a change in the lab sequence. As shown in Table 2, the total dissolved iron analysis was not explicitly covered in the introductory labs. Because students were allowed to develop their own plans for analyzing their water samples, many chose not to analyze for iron. These results suggest that optional techniques are less likely to be completed by students. That means that techniques recommended as part of the curriculum by the ACS, such as spectrophotometry, should be explicitly included in the lab sequence (American Chemical Society Committee on Professional Training, 2015).

\subsection{Word Frequency Analysis}

The word frequency analysis seen in Figure 5 shows that students tend to be 'comfortable' and 'interested' while in the laboratory. However, in 2017 roughly equal numbers of students were 'bored', 'excited', and 'confused'. A closer look at the bored population yielded some interesting results. In 2017, Mechanical Engineering majors comprised 29\% of the students surveyed.

However, they comprised more than $60 \%$ of the bored population. In 2018 , this result was not observed, i.e., the rate of Mechanical Engineering majors stating they were bored normalized to the course population was consistent with other majors. Regardless of their stated emotion, Mechanical Engineering majors in 2017 and 2018 showed no significant difference in their ACS Full Year General Chemistry standardized exam scores (i.e., ACS exam scores were consistent between bored and not bored populations). This result suggests that numerous external factors may contribute to affective environment of the course and that multi-year sampling is needed to monitor changes in attitudes. In the 2018 panel of Figure 5, the percentage of 'confused' students doubled from the previous year. This change can likely be attributed to changes in the lab sequence. In 2018, students remediated then analyzed a sample for total hardness. Due to the limits of a two-hour lab period, a portion of the analysis was completed for them and numbers were provided. Students indicated that truncating the procedure for them led to confusion. Though the results of the affective learning environment are generally favorable, more work needs to be done to establish the relatively low ranking of 'creative'. 


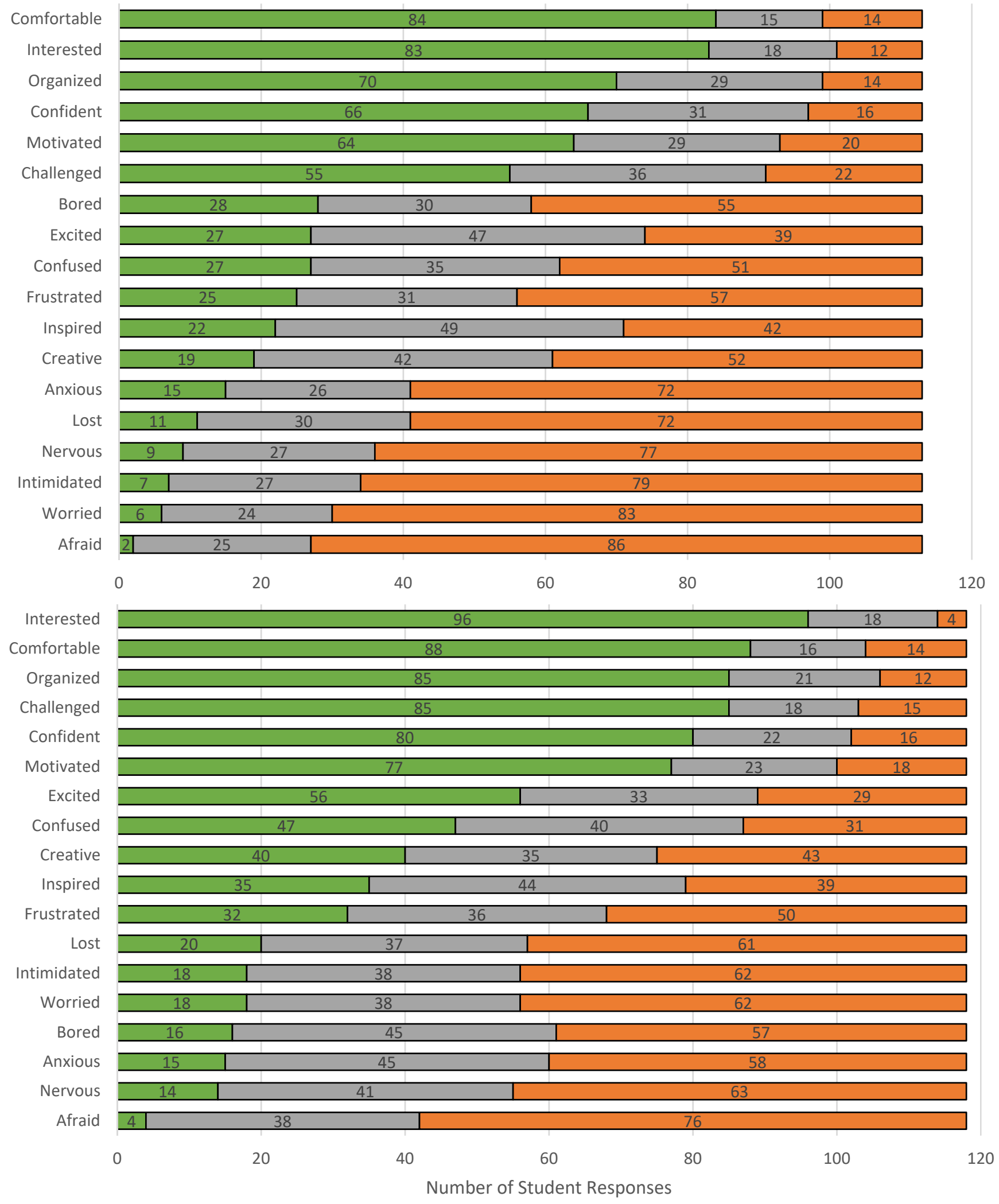

$\square$ Experienced $\square$ No Response $\quad \square$ Did Not Experience 
Figure 5. Frequency of words describing affective experience of student in the $\mathrm{CH} 102$ laboratory. Top panel summarizes results from 2017 and bottom panel from 2018 survey. Bands in green indicate an emotion experienced in the laboratory (left side of bar graph); orange indicate the term was not experienced (right side); and grey indicate no response (middle field).

\subsection{Interest in STEM and Achievement of Course Goals}

In addition to the word frequency analysis, students provided feedback on whether the lab sequence increased, decreased, or did not change their interest the field of chemistry and also their interest in pursuing research. While just under half (49\%) of the students surveyed reported an increased interest in the field of chemistry, over $60 \%$ reported an increased interest in research.

In terms of achieving the content goals of the course, the water quality sequence aligned well with learning objectives for the course. Table 3 shows the correlation between the lab topics and learning objectives from select lessons. This alignment was reflected in an $89 \%$ agreement from students surveyed that the lab sequence reinforced topics covered in the classroom.

Table 3. Laboratory sequence alignment with lesson learning objectives addressed in the classroom.

\begin{tabular}{ll}
\hline \multicolumn{1}{c}{ Lab Topic } & \multicolumn{1}{c}{ Lesson Learning Objective } \\
\hline Total Hardness Titration / Remediation & $\begin{array}{l}\text { Classify ionic compounds by solubility; Determine if a } \\
\text { precipitate will form } \\
\text { Classify acids and bases applying Brønsted-Lowry } \\
\text { definition; Recognize buffers and describe what a buffer } \\
\text { does }\end{array}$ \\
Total Alkalinity Titration & $\begin{array}{l}\text { Determine substance oxidized or reduced; Identify } \\
\text { oxidizing agent; Assign oxidation numbers } \\
\text { Compare and contrast behavior of soluble ionic } \\
\text { Total Dissolved Iron (Spectrophotometrounds and covalent compounds in water }\end{array}$ \\
Total Dissolved Solid Measurement & Classify acids and bases according to pH value \\
\hline
\end{tabular}

In addition to the learning objectives, the lab sequence ties in well with Student Learning Outcomes designated for the course by our Department and institution. These four outcomes are for students to: develop practices for thinking scientifically by deducing, predicting, and explaining scientific observations; explain and apply foundational chemistry concepts; develop practices for learning independently (intellectual self-reliance); and build practices to work within teams and lead their peers. With the exception of intellectual self-reliance the Student Learning Outcomes are clearly addressed by providing students with a research inspired, chemistry project that is completed in groups.

Though surveys were not administered before Spring 2017, the ACS Full Year General Chemistry standardized exam was administered to all students in the two semesters prior. The course average on the score showed no statistically significant changes following the adoption of the new laboratory sequence. While the water quality lab sequence does not appear to have 
improved students' abilities to explain and apply foundational chemistry concepts, the potential improvement to the affective learning environment is encouraging.

\section{Conclusions and Future Work}

The water quality laboratory sequence implemented in $\mathrm{CH} 102$ shows great promise for improving student engagement in a core chemistry course. The sequence addresses content goals set by the institution and guidance from the American Chemical Society. It is a hand-on experience that balances expository instruction in introductory labs with inquiry-based instruction in the form of a research inspired project. This facilitates learning opportunities while minimizing frustration with learning a new skill. The ability to propose, collect, and analyze their own water sample affords additional opportunities for students to more actively participate in their learning experience. This sequence, after some adjustments, has been designed to be completed within the allocated lab period of two hours. After preliminary analysis, student feedback on the affective learning environment is positive, but with potential areas of improvement.

Future modifications to the lab sequence include adding a stand-alone electrochemistry lab along with an independent experiment for students to individually measure the $K_{a}$ of a weak acid. These additions to the lab curriculum will address student requests for additional time in the lab to cover a broader range of topics as well as the Student Learning Outcome of developing practices for intellectual self-reliance.

\section{Disclaimer}

The views expressed are those of the authors and do not reflect the official policy or position of the US Army, Department of Defense, or the US Government.

\section{References}

American Chemical Society Committee on Professional Training Undergraduate Professional Education in Chemistry: ACS Guidelines and Evaluation Procedures for Bachelor's Degree Programs American Chemical Society: Washington, DC, 2015.

Bybee, Rodger W. NGSS and the Next Generation of Science Teachers Journal of Science Teacher Education 2014, 25(2), 211-221.

Chase, A.M.; Clancy, H.A.; Lachance, R.P.; Mathison, B.M.; Chiu, M.M.; Weaver, G.C. Improving Critical Thinking Via Authenticity: the CASPiE Research Experience in a Military Academy Chemistry Course Chemistry Education Research and Practice 2017, 18, 55-63.

Cooper, Melanie M. Chemistry and the Next Generation Science Standards Journal of Chemical Education 2013, 679-680.

Galloway, K.R.; Bretz, S.L. Measuring Meaningful Learning in the Undergraduate Chemistry Laboratory: A National, Cross-Sectional Study Journal of Chemical Education 2015, 92, 20062018. 
Galloway, K.R.; Malakpa, Z.; Bretz, S.L. Investigating Affective Experiences in the Undergraduate Chemistry Laboratory: Students' Perceptions of Control and Responsibility Journal of Chemical Education 2016, 93, 227-238.

Kegley, S.E.; Abdella, B. Water Treatment Instructor Guidebook Norton: NY, 2003.

Kegley, S.E.; Landfear, D.; Jenkins, D.; Shomglin, K. Water Treatment: How Can We Make Our Water Safe to Drink; Norton: NY, 2004; pp 43-47.

Korn, M. Chemistry Departments Try to Attract More Students by Retooling the Major; Universities begin to overhaul traditional curricula in science field that some worry is churning out too few graduates for nation's needs Wall Street Journal [Online] 12 April 2015 https://0search.proquest.com.usmalibrary.usma.edu/docview/1672433445?accountid=15138 (accessed 17 April 2017).

Larsen, R.G.; Monette, S.; Messerle, L. Strategies for Chemistry Instructional Laboratory and Curriculum Design from Innovations and Renovations: Designing the Teaching Laboratory ACS Symposium Series American Chemical Society: Washington, DC, 2013.

Maienschein, J. Scientific Literacy Science 1998, 281, 917.

Mayo Clinic. Nutrition and healthy eating, September 2017. Accessed December 2018 from: http://www.mayoclinic.org/healthy-lifestyle/nutrition-and-healthy-eating/in-depth/water/art$\underline{20044256}$

National Research Council. National Science Education Standards; National Academy Press: Washington, DC, 1996.

National Research Council. A Framework for K-12 Science Education: Practices, Crosscutting Concepts, and Core Ideas. National Academies Press, 2012.

National Research Council. Undergraduate Chemistry Education: A Workshop Summary; National Academy Press: Washington, DC, 2014.

Obenland, C.A.; Kincaid, K.; Hutchinson, J.S. A General Chemistry Laboratory Course Designed for Student Discussion Journal of Chemical Education 2013, 91, 1446-1450.

Pedaste, M., Maeots, M., Siiman, L., de Jong, T., van Riesen, S.A.N., Kamp, E.T., Manoli, Constantinos C., Zacharia, Z., Tsourlidaki, E. Phases of inquiry-based learning: Definitions and the inquiry cycle Educational Research Review 2015, 14, 47-61.

Svinicki, M.D.; McKeachie, W.J. McKeachie's Teaching Tips: Strategies, Research, and Theory for College and University Teachers 14 $4^{\text {th }}$ ed; Wadsworth Cengage Learning: United States, 2014. 
Tomasik, J.H.; Cottone, K.E.; Heethuis, M.T.; Mueller, A. Development and Preliminary Impacts of the Implementation of an Authentic Research-Based Experiment in General Chemistry Journal of Chemical Education 2013, 90, 1155-1161.

World Health Organization. Drinking-water. February 2017. Accessed December 2018 from: https://www.who.int/en/news-room/fact-sheets/detail/drinking-water 